\title{
A Deep Learning Model to predict the Industry Readiness of Engineering Students Community
}

\author{
Ashok Murugesan ${ }^{1 *}$, Kumar Ramasamy ${ }^{2}$, Umadevi Ashok $^{3}$ and Revathy Pandian ${ }^{4}$ \\ ${ }^{1}$ Assistant Professor/CSE, Rajalakshmi Institute of Technology, Chennai. \\ ${ }^{2}$ Professor/CSE,Dhirajlal Gandhi College of Technology,Salem. \\ ${ }^{3}$ Assistant Professor/MBA,SRMValliammai Engineering College, Chennai. \\ ${ }^{4}$ Professor/MBA, Velammal Engineering College,Chennai.
}

\begin{abstract}
Industry readiness of Engineering students community is a big challenge in the recent campus recruitments. 21 st century skills are completely mapped with the technical and non - technical knowledge background of the engineering graduates. In this paper the work narrated the process of identifying the parameters for skill assessment of the candidates and derived a learner model using deep learning framework. Further the model can be used to predict the employability readiness of candidates.
\end{abstract}

\section{Introduction}

Campus placements are the vital key indicator for the students to choose their professional course of study. After enrolling in the course, the orientation of students towards job profiling depends on the job market. In this work, we are considering engineering students community. During their pre final and final year courses of study, their complete starvation sticks to placement oriented programs. Their preparation comprises of both technical as well as non technical domains. Such programs are focusing very rarely in problem solving domain. With respect to the statistics, $10 \%$ of students landing in high band packages, $70 \%$ of students landing in average band packages and $20 \%$ students are moving for higher studies or exiting from the campus without placements.

Our work is ready to concentrate with $20 \%$ of students exiting campus without placements. From their second year of course onwards, 21st century skill based parameters must be explained and train them using the outcome of the model derived. A parameterized framework can be designed using the convolutional neural network and analyze the outcome of the students in the regular intervals. This will enhance the placement opportunity for the identified community.

Ronal et al[1] provided the results of their tool by supporting self learning with course engagement. Kaveri et al[2] correlated the parameters for learner's engagements. Allison et al[3] illustrated personal learning portfolio of different types of candidates. Zahra et al[4] conducted an experimental investigation with 30 students and conveyed the behaviour of learners with their emotions using non survey based system. Lin et al[5] performed a comparative survey of different types of feedback based learner models. Rajendran et al[6] discussed the frustrations of learners when the academic experts providing feedback to them. In turn he also conveyed about the role of stress in different types of learning environment. Tran and Meachean[7] summarized the routines for enhancing the learner's experience using extended learning systems. They have incorporated test, analytics, administration and flipped learning in their framework. Muljo et al[8] produced a prototype for online learning pertaining to higher education. Technology acceptance model designed by them had yielded a fruitful measure in 21 st century skills of the students. Rahila et al[9] depicted a model to predict the growth of learner's performance by assessing the attributes of the learners in the weekly assessments. Ananthi and Nazreen [10] illustrated the user's experience in learning management systems. Also they have identified the behavioral analytics of the interdisciplinary users of the system. Justian and Esther[11] listed the systematic survey of learning teachnologies in terms of learning environments, learning process and learning outcome. Bart et al[12] created a learning frameworks which evaluates the students community using design and evidence based research. Through this they are analysing the positive impact of learner's attitudes.

*Corresponding author: ashok.m@ ritchennai.edu.in 


\section{Literature Survey}

An observation[1] of course attainment was mapped with self learning in a regulated fashion. Sample size of the experiment was restricted to 263 learners. They had used four parameters to assess self learning. It had reflected a positive correlation with the attempt. They had a zero significance in learner behavior management. A hypothesis[2] based approach was elaborated with learner's engagement. Sample size of the experiment was restricted to 59 users. They had used thirteen parameters for learner analysis. They had extracted four parameters as mandate through feature extraction. Their empirical results demonstrated the outcome of the framed hypothesis.

A complete evaluation[3] of learner behavior while engaging a specific course was discussed. Sample size of the experiment was restricted to 750 users. They had used five parameters for learner's engagement analysis. They had derived the descriptive statistics of aforementioned five attributes. A fuzzy based approach[4]followed to analyze the emotions of learners. They had designed two questionnaires to retrieve the attributes of learners. Sample size of the experiment was restricted to 32 users. They had used six parameters to narrate their research flow.

Three different data models[5] were focused. They were linked with analytics based front end. Six different parameters were analysed to measure the learning strategies.70K online learners were tracked. Seven different parameters were identified for the learners and projected in the dashboard. An UI[6] based interactive tool was discussed. It had received comments from all the learners and respond with the learners had frustrated experience.600+ school students were involved in this exercise. It witnessed the outcome of the learner's attempt on the static goals.

Extended learning systems[7] was built with four different zones. Learner's behavior was assessed .Integrated curriculum design was focused. Adaptive course management had issued its provision. A model for flipped learning to incorporate the aforementioned three parameters. Sample size of the experiment was restricted to 60 learners. A prototype [8] for online based higher education was discussed. Five parameters were designed to analyze the learner in online mode. Sample size of the experiment was restricted to 200 users. They have tried to solve the specific challenges in online learning too.

Three different machine learning[9] algorithms were incorporated to predict the test performance of the learners. They had used six variables to trace the history for the learning. They had repeated the experiment for 16 weeks to gather the data for complete analysis. They had incorporated both online and offline activities. Online activities served as the catalyst for the research. Size of the experiment was restricted to 99 users. User experience[10] in the learning domain played a vital role for complete involvement and engagement in course learning. Adaptive learning based data were fed for the learner based on the learning trend. They have employed data mining techniques to analyze the user experience and recommend the upgrades for the subsequent learning domain.

A systematic literature1[11] review about the learning strategies, evaluations and implementation beds were discussed. They had organized the literature through three different sections. Section 1 narrated the methods of evaluation. Section 2 illustrated the behavioural aspects of learner in the learning domain. Section 3 depicted the limitations and recommendations of the analytics in technology based learning enhancement. Learning[12] analytics were captured in terms of learning strategies, framework of evaluation and predictive modeling. Sample size of the experiment was restricted to 1076 users. They had suggested topics to improve the phase of scoring. They had elaborated the process of strategy shifting from types of learning groups.

\section{Methodology}

\subsection{Identification of Parameters}

The parameters responsible for industry readiness were Productivity Rate, Self Learning, Responsible Engagement and Skill for different types of learning community. To create the framework, the parameters were treated as Usage Quotients (UQ). Every Parameter was described as the ratio of two or more numerical attributes. It would be easy to perform computations or predict using the data sets.

Productivity $(\mathrm{PR})=$ Time spent for Professional growth per day/14 hours

Self Learning Quotient $(S L Q)=A+B$ where $A \& B$ reflects $(1)$

$\mathrm{A}=\%$ of syllabus covered through self learning

$\mathrm{B}=\%$ of content beyond the syllabus learning

Responsible Engaging Quotient $(R E Q)=C / D$

$\mathrm{C}=$ Total Number of Professional Activities Participated

$\mathrm{D}=$ Total Number of Professional Activities conducted per Academic Year

Skill Quotient $(S Q)=(E+F) / G$ 


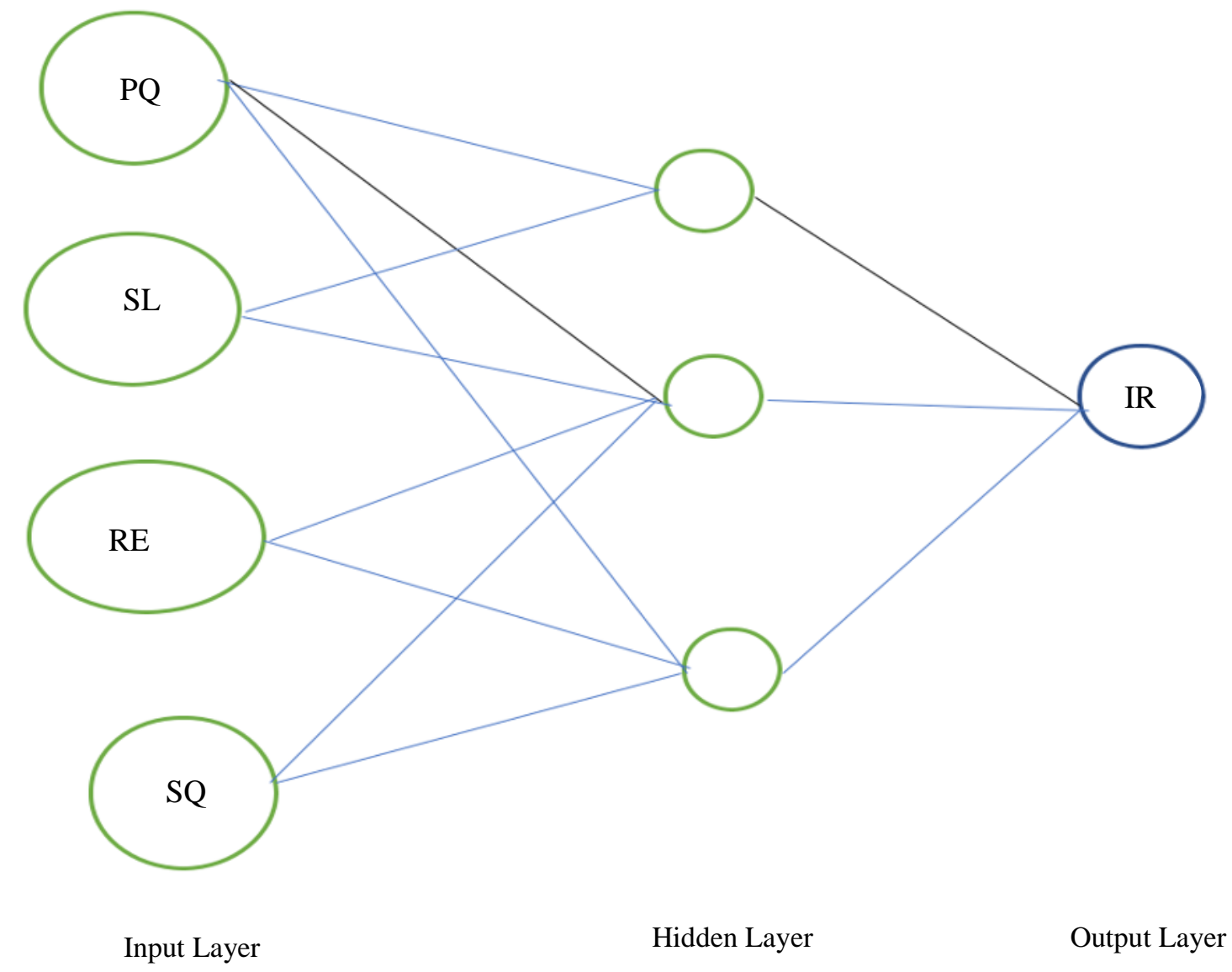

Fig 1. ANN Model

E=Number of Problems narrated properly

F=Number of Problems methodology suggested

$\mathrm{G}=$ Total Number of Problems provided as a part of Placement Curriculum

\subsection{Parametric Framework}

Industry Readiness Quotient (IRQ) was defined as the variant for storing the influence of (1), (2), and (3)

$$
I R Q=P Q+S L Q+R E Q+S Q
$$

The results of (4) can be expressed as continuous function and narrated as follows.

$\mathrm{f}($ IRQ $)=\{$ IRQ $>=2$, Subject has the impact of Placed Category; Otherwise, Nonplaced Category.

\subsection{Learner Modeling}

900 students per year were involved in campus placements. The model is trained using 10years data. The datasets belong to the non autonomous private engineering college affiliated to a state university in Tamilnadu.

\section{Experimental Investigation}

The following table 1 represents the Actual statistics and table 2 represents the comparative study.

\begin{tabular}{|c|c|c|c|}
\hline Year & $\begin{array}{c}\text { Total } \\
\text { Students }\end{array}$ & $\begin{array}{c}\text { \%of Placed } \\
\text { Candidates }\end{array}$ & $\begin{array}{c}\text { \%of Non } \\
\text { Placed } \\
\text { Candidates }\end{array}$ \\
\hline 2011 & 895 & 74 & 13 \\
\hline 2012 & 900 & 82 & 8 \\
\hline 2013 & 890 & 79 & 20 \\
\hline 2014 & 892 & 67 & 20 \\
\hline 2015 & 888 & 84 & 12 \\
\hline 2016 & 894 & 92 & 7 \\
\hline 2017 & 891 & 89 & 10 \\
\hline 2018 & 892 & 88 & 11 \\
\hline 2019 & 897 & 93 & 6 \\
\hline 2020 & 893 & 91 & 8 \\
\hline
\end{tabular}

Table 1.Actual Statistics 


\begin{tabular}{|c|c|c|c|c|}
\hline Year & Total Students & $\begin{array}{c}\text { Actual number } \\
\text { Of students placed }\end{array}$ & $\begin{array}{c}\text { Outcome of the parametric } \\
\text { model }\end{array}$ & $\begin{array}{c}\text { Outcome of the } \\
\text { learner model }\end{array}$ \\
\hline 2011 & 895 & 74 & 68.08 & 66.6 \\
\hline 2012 & 900 & 82 & 75.44 & 73.8 \\
\hline 2013 & 890 & 79 & 72.68 & 71.1 \\
\hline 2014 & 892 & 67 & 61.64 & 75.3 \\
\hline 2015 & 888 & 84 & 77.28 & 82.8 \\
\hline 2016 & 894 & 92 & 84.64 & 80.1 \\
\hline 2017 & 891 & 89 & 81.88 & 79.2 \\
\hline 2018 & 892 & 88 & 80.96 & 83.7 \\
\hline 2019 & 897 & 93 & 85.56 & 81.9 \\
\hline 2020 & 893 & 91 & 83.72 & \\
\hline
\end{tabular}

Table 2.Comparative Study

Actual statistics of students as mentioned in Table 1.1 are compared with parametric model and learner model. The accuracy of the learner model during training phase reached $92 \%$.The parametric evaluation also reached $90 \%$ accuracy when compared with the actual statistics in Table 1.2.Students opted for higher studies are omitted from this investigation.

$11 \%$ variation observed when we had compared the results of our model with Skill Assessment Software of XYZ Private Limited. By considering the legal issues, the name of the company was renamed.

Low level and high level indicators[1,5] of granularity could be anlaysed by our parametric model in terms of their engaging parameters. Different types of learner modeling [2,6] could be estimated through the proposed parametric and outcome based models. Self regulation parameters [3,7] could be correlated with the proposed parameters and feature extraction could be done. Emotional modeling $[4,8]$ could be enhanced with the proposed parametric modeling.

\section{Conclusion \& Future Work}

The learner model will be rebuilt with different architectures of neural network. The issues of over fitting and under fitting on the designed model need to be analysed with larger datasets. Through this system, the portion of non-placed students can be filtered and properly monitored during their initial course of study itself.

\section{References}

[1] R. Antonio Pérez-Álvarez, J. Maldonado-Mahauad, K. Sharma, D. Sapunar-Opazo and M. Pérez-Sanagustín, "Characterizing Learners' Engagement in MOOCs: AnObservational Case Study Using the NoteMyProgress Tool for Supporting Self-Regulation," in IEEE Transactions on Learning Technologies, vol. 13, no. 4, pp. 676-688, 1 Oct.-Dec. 2020, doi: 10.1109/TLT.2020.3003220.
[2] Kaveri, S. Gunasekar, D. Gupta and M. Pratap, "Decoding Engagement in MOOCs: An Indian Learner Perspective," 2016 IEEE Eighth International Conference on Technology for Education (T4E), Mumbai, 2016, pp. 100-105, doi: 10.1109/T4E.2016.027.

[3] Allison Littlejohn, Nina Hood, Colin Milligan, Paige Mustain,Learning in MOOCs: Motivations and selfregulated learning in MOOCs, The Internet and HigherEducation,Volume29,2016,Pages 40-48,ISSN 10967516,https://doi.org/10.1016/j.iheduc.2015.12.003.

[4] Z. Karamimehr, M. M. Sepehri and S. Sibdari, "Automatic Method to Identify E-Learner Emotions Using Behavioral Cues," in IEEE Transactions on Learning Technologies, vol. 13, no. 4, pp. 762-776, 1 Oct.-Dec. 2020, doi: 10.1109/TLT.2020.3020497.

[5] K. Liu, S. Tatinati and A. W. H. Khong, "ContextBased Data Model for Effective Real-Time Learning Analytics," in IEEE Transactions on Learning Technologies, vol. 13, no. 4, pp. 790-803, 1 Oct.-Dec. 2020, doi: 10.1109/TLT.2020.3027441.

[6] R. Rajendran, S. Iyer and S. Murthy, "Personalized Affective Feedback to AddressStudents' Frustration in ITS," in IEEE Transactions on Learning Technologies, vol.12, no. 1 , pp. 87-97, 1 Jan.-March 2019, doi: 10.1109/TLT.2018.2807447.

[7] T. P. Tran and D. Meacheam, "Enhancing Learners' Experience Through ExtendingLearning Systems," in IEEE Transactions on Learning Technologies, vol. 13, no. 3, pp. 540-551, 1 July-Sept. 2020, doi: 10.1109/TLT.2020.2989333.

[8] H. H. Muljo, A. S. Perbangsa and B. Pardamean, "Online learning prototype for higher education," 2017 International Conference on Information Management andTechnology (ICIMTech), Yogyakarta, 2017, pp. 49-53, doi: 10.1109/ICIMTech.2017.8273510.

[9] R. Umer, T. Susnjak, A. Mathrani and S. Suriadi, "A learning analytics approach: Using online weekly student engagement data to make predictions on student performance," 2018 International Conference on Computing, Electronic and ElectricalEngineering (ICE Cube), Quetta, 2018, pp. 1-5, doi: 
10.1109/ICECUBE.2018.8610959.

[10] Sheshasaayee and M. N. Bee, "Evaluating user experience in moodle learning management systems," 2017 International Conference on Innovative Mechanisms for Industry Applications (ICIMIA), Bangalore, 2017, pp. 735738, doi: 10.1109/ICIMIA.2017.7975562.

[11] J. Knobbout and E. Van Der Stappen, "Where is the Learning in Learning Analytics? A Systematic Literature Review on the Operationalization of Learning-Related Constructs in the Evaluation of Learning Analytics Interventions," in IEEETransactions on Learning Technologies, vol. 13, no. 3, pp. 631-645, 1 July-Sept.

2020, doi: 10.1109/TLT.2020.2999970.

[12] Rienties B., Cross S., Zdrahal Z. (2017) Implementing a Learning Analytics Intervention and Evaluation Framework: What Works? In: Kei Daniel B. (eds) Big Data and Learning Analytics in Higher Education. Springer, Cham. https://doi.org/10.1007/978-3-319-065205_10 